\title{
Performing Wellness: Playing in the Spaces Between Music Therapy and Music Performance Improvisation Practices
}

\author{
Deborah Seabrook $^{1 \text { * }}$ \\ 1 Concordia University, Canada \\ *deborah.seabrook@gmail.com
}

Received: 31 May 2017 ; Accepted: 29 September 2017 ; Published: 1 November 2017

Editor: Michael Viega Reviewer: Jason Noone

\begin{abstract}
This is the accompanying paper to an arts-based pilot project that musically explored interdisciplinarity between improvisation in music therapy and music performance. A culminating concert that brought elements of music therapy improvisation to the stage (available for viewing online) is where the vital learning from this project resides. This written piece additionally articulates philosophical, theoretical and practical concepts and questions that arose from the investigation. Elements of music therapy and music performance improvisation are compared, contrasted, and combined from within the author's experience. The emergent potential of improvised musical performances for health and wellbeing is also discussed.
\end{abstract}

Keywords: Improvisation, music therapy, music performance, interdisciplinary, artsbased research

\section{Introduction}

\begin{abstract}
For this concert I'm inviting you to listen to music in a way that is perhaps more accustomed to music therapy than to performance. Where in performance, we might traditionally listen for the musicality of the compositions and for the performer's abilities, instead this concert is inviting audience members to listen to the message embedded in the music, and in particular, to listen for the person within the music (...). This idea of "self in sound" is very important in the music therapy that I practice. Each of the pieces tonight involves this idea, and I invite you to listen in that way.
\end{abstract}

These are excerpts from the opening remarks that I gave at a concert entitled Performing Wellness. Rather than being a stand-alone event, the concert was part of a pilot study I conducted exploring areas of overlap and distinction between improvisation in music therapy and improvisation in music performance. This written piece is an accompaniment to that concert. I will begin by presenting and defining core concepts and sharing the experiences that led me to prepare and perform this work. A literature review highlights ways that other music therapists and performers are exploring interdisciplinarity between these areas. Finally, themes that emerged for me through the process of creating and executing this concert in the context of a pilot research study are explored and discussed. While the main focus of this paper is the intersection between music improvisation in music therapy and music performance, it is not meant 
to be an exhaustive academic discussion of this topic. Rather, it is a focused, and at times, personal account of an interdisciplinary pilot study wherein I used my self and my music to explore what I experience as an intersectionality between improvisation in those two disciplines.

\section{Setting the Stage: Improvisation in Music Therapy and Music Performance}

Music improvisation in any context or discipline is the instantaneous musical creation of making up and playing music in the moment; it "exists exclusively in the present, both as a creative impulse and as a musical experience" (Neeman, 2014, p. 39). Neeman distinguishes between the "ideal existence" that "nonimprovised interpretation" strives for, which "perfectly captures the original intentions of the composer" and the impermanent "concrete existence" of improvisation, concerned only with each single performance (p. 39). We can then consider how music improvisation is conceived in the disciplines, contexts, and practices of music performance and music therapy.

In Western art music ${ }^{1}$, a performance is regarded as "a distinct and separate goal from the study of music and is almost always set apart by an external formality" (e.g. a concert, recording session, or an audition) (Gordon, 2006, p. 3-4). Improvisation within the performance discipline is typically enacted by a trained musician and perceived as "a single event, which can contain elements of unpredictability" (p. 4).

Contrastingly, in the types of improvisation used in music therapy (also called clinical improvisation ${ }^{2}$ ), the client improvises while playing an instrument or singing, selecting "any musical medium within their capabilities" (Bruscia, 2014, p. 130); the music therapist facilitates and supports this process by improvising using musical and therapeutic techniques from music therapy literature (e.g. Gardstrom, 2007; Lee \& Houde, 2011; Wigram, 2004). While the music therapist is a trained clinical improviser, previous musical training is not required on the part of the client (Bruscia, 2014). An important distinguishing quality of clinical improvisation is that it is always created in the service of the client's therapeutic process.

Improvisation for music performance and improvisation in music therapy respectively, require distinct players (trained musicians in the case of performance, and a client and therapist in the case of music therapy); occur in different contexts (while clinical improvisation can occur on a concert stage or performance, particularly within the framework of Community Music Therapy (Ansdell \& Stige, 2015), it can also occur in a clinical setting, unlike music performance practices); and have unique motivations (where the purpose of clinical improvisation is exclusively in the interest of the health and wellbeing of the client, unlike performance improvisation). In addition to these distinctions, there are vibrant areas of commonality between performance and clinical improvisation. For example, both involve music improvisation and require intra and inter-personal musical communication. The purpose of this pilot study was to musically explore and articulate areas of intersection between music improvisation in music therapy and performance, and to challenge the boundary between the disciplines. In some ways, this interdisciplinarity has been musically explored by other music therapists and performing musicians.

\section{Examples of Interdisciplinary Music-Making}

There are instances of both music therapists and music performers bridging the traditional boundaries between these disciplines. The following highlights relevant work from each of these perspectives.

Non-clinical improvised performance in music therapy. When performance is discussed in music therapy literature, it includes clients to some degree: clients performing solo music that their music therapist(s) supported them in creating, clients performing alongside their music therapist(s), or music therapists performing in honour or in lieu of a specific (group of) client(s) (Aigen, 2014). These performances are 
done in the service of the clients' goals, with indications and contraindications carefully considered (Young \& Nichol, 2011). I have not uncovered literature discussing music therapists performing music therapy related concerts without their clients being directly involved, however this is not to say that it is not occurring. I have attended several concerts where music therapist, Colin Andrew Lee, performed solo improvisations that featured excerpts from his former clients' clinical improvisations (Lee, 2011). The concerts had aesthetic aims and were not created in collaboration with the client(s) or to meet the clients' needs. These concerts were intended to act as an artistic expression of Lee's experiences as a music therapist (Lee, personal communication, May 22, 2017). In another concert, Lee performed clinical improvisations with the Penderecki String Quartet in the role of the clients; the aim of the concert was again aesthetic. Most recently, Lee performed a solo concert of improvised compositions entitled Music for Contemplative Landscapes (2016); as the title suggests, Lee's intention was to offer the audience a musical aesthetic suitable for reflection and contemplation (Lee, personal communication, May 22, 2017). Lee's concerts can be viewed as interdisciplinary works, by a client's musical materials as the basis for improvisation and by intending to facilitate a particular experience for audience members (ie. contemplation). While following Western classical music performance conventions, he combines elements of clinical and performance improvisation. Music performers and composers have likewise explored bringing elements of music therapy into their work.

'Therapeutic' performance practice. The 'therapeutic' experience of performing improvisation has been affirmed by many musicians including jazz musicians like Charlie Parker (Reisner, 1977) and 'free' improvisers like Steven Nachmanovitch (Nachmanovitch, 1991). Some performers also identify a 'therapeutic' impact for audiences. As a comprehensive review of music performance for this purpose is beyond the scope of this article, I will share a contemporary example of this by exploring the work of composer and performer Daniel Brandes. Brandes intends for his music to invite the audience into an "exposed and vulnerable space" which he refers to as "Sabbath space" (2015, Section 3, para. 2). Brandes' intention in cultivating this space is to offer a sense of community and an experience of deep calm for the audience and performer(s). Brandes' performance goals can be viewed as therapeutic because his intentions are exclusively focused on the emotional and interpersonal impact of the performance on the audience. This example illustrates one way in which music performance can incorporate interdisciplinarity by involving music therapy-type principles.

Music that combines elements of music performance and music therapy, like that of Lee and Brandes, resonates with me as both an improvising musician and a music therapist. It is my experience of this interdisciplinary identity that largely motivated this study.

\section{An Interdisciplinary Identity}

In my work as a music therapist, I have had the privilege of making music alongside people from many different life situations, at the end of their life in palliative care, in mental health care, and with a variety of special needs. My music therapy training emphasized music-centeredness ${ }^{3}$, and this remains a core element of my approach, along with person-centered (humanistic) psychotherapy, and feminist therapy. The clinical improvisation models that I most frequently draw upon are music-centered models: Creative Music Therapy (Nordoff, Robbins, \& Marcus, 2007) and Aesthetic Music Therapy (Lee, 2003). As a music therapist and music therapy supervisor, I often invite people I am working with to explore and process their material through live music-making, particularly clinical improvisation. During clinical improvisation, my whole self, including my music and musical self, is at the service of the client's health and wellbeing. When improvising with someone as a music therapist, I have often felt a deep connection and understanding between us, and I have been profoundly and irrevocably shaped by this work. I view my music therapy self as one aspect of who I am a musician, with another being my music performance self. 
I was trained in classical piano performance, music theory, and history through the Royal Conservatory of Music (Canada). During my undergraduate degree, I was introduced to Keith Jarrett's improvised piano performances and composers that incorporate elements of unpredictability into their music like John Cage. I soon began performing in a free-improvisation ensemble and composing music that incorporated written notation and improvisation; the genre within which I continue to improvise as a performer is most accurately identified as "free-improvisation" ${ }^{4}$. When performing in a free-improvisation ensemble, I do not have a responsibility for the other players' health and wellbeing as I do in clinical improvisation. Instead, I feel that we are each equally responsible for the musical outcome, and we can freely contribute to the music however we would like.

Despite these distinctions between how I improvise in music therapy and music performance, I also experience a permeable boundary between these practices as a music-centered music therapy clinician and educator, and as an improvising performing musician. For example, when I improvise as a music therapist, I draw on musical theory and my technical skills to provide the best experience for the person I am working with; I also draw on this knowledge and skillset during improvisational music performance. Likewise, as an improvising performer I engage in deep listening, aiming to hear and respond to the essence of the music itself rather than the individual notes of the other players; I also bring these intentions to clinical improvisation. For me, to be a music therapist is to be steeped in interdisciplinarity; as a music therapist I actively draw on theory, practice, and skills from music, music therapy, and psychotherapy disciplines (to name a few).

I wanted to explore the intersection between music improvisation in music therapy and performance using music itself; therefore I used arts-based research principles to create and contextualize this pilot study.

\section{A Concert as Research}

\section{Research-Creation}

There is a growing body of arts-based research (or 'research-creation', as it is also identified in Canada) in both music therapy (Austin et al., 2016; Viega, 2016; Viega \& Forinash, 2016) and performance studies (Cobussen, 2014; Kershaw, 2009) that affirm artistic creation as a unique and necessary way of cultivating, exploring, understanding, and disseminating knowledge and experience. I chose research-creation, an arts-based method, that develops knowledge through artistic expression, scholarly investigation, and experimentation (Social Sciences and Humanities Research Council, 2016) for this project, because I wanted to experience the intersection between these two fields and to tacitly explore it with the medium I was studying. I intended for this project to uncover insights both inherent to the phenomenon itself and "unknowable by other means" (Seabrook \& Arnason, 2010, abstract).

Chapman and Sawchuck (2012) propose four overlapping ways of understanding research-creation. Two of these are particularly relevant to this concert: "research-forcreation" and "creation-as-research" (p. 15). Research-for-creation involves "the tracking down of precedents for one's creative ideas, the articulation of a cluster of concepts, as well as trying out different prototypes or iterations" ( p. 16). As part of my research project, the concert twinned with this paper included three distinct pieces (see Appendix A), or "clusters of concepts", each exploring a different idea. The concert was a pilot project, a place to try out different iterations of these concepts as models for future use. I simultaneously performed my understanding of those concepts and worked through them in the moment.

Overlapping with the notion of research-for-creation is creation-as-research, where creation is required for research to emerge:

It is about investigating the relationship between technology, gathering and revealing through creation (following Franklin, 1992, and Heidegger, 1977, where 'technolo- 
gy' connotes a mind-set and practice of crafting as much as it does 'equipment'), while also seeking to extract knowledge from the process. Research is more or less the end goal in this instance, although the 'results' produced also include the creative production that is entailed, as both a tracing-out and culminating expression of the research process. (Chapman \& Sawchuck, p. 19)

Creation-as-research was also my intention with this concert: to creatively perform elements of improvisation in music-centered music therapy and music performance practices while simultaneously uncovering the shape of the inquiry.

\section{Audience Feedback}

The concert audience engaged in reflection and dialogue, both interpersonally and intermusically. For example, the audience was offered a detailed programme and spoken remarks that contextualized the performance and invited them to participate in the concert in specific ways. Audience members were invited to contribute directly to the music by writing down a feeling or emotion on a slip of paper (provided) prior to the concert; five of these were randomly selected to be performed in the piece "Sounding the Emotional Aesthetic Environment". Due to the additional intention of this initial concert/pilot project to fulfill a single PhD course credit, written audience or performer feedback was not sought and therefore, an ethics review was not required.

The concert itself is the primary outcome of this pilot research-creation process ${ }^{5}$. I invite you to read through the programme notes (Appendix A) before watching the concert, available for online viewing through the following links:

https://youtu.be/IMNw1x2DQBk

https://youtu.be/Srrg3tjvuhM

https://youtu.be/uomAzj4KG5Y

https://youtu.be/vMSRlD0P5QU

https://youtu.be/ZpgXVlXILkw

https://youtu.be/113kd1_y5hs

https://youtu.be/Lj40uOE6SM0

In addition to this, I share my personal reflections on the experience in the following section.

\section{Reflections on "Performing Wellness"}

My experience preparing and performing this material uncovered three main areas of reflection: a unique improvisation experience, material and relational areas of interdisciplinarity, and interdisciplinary tensions.

\section{Integrating Interdisciplinarity: A Unique Improvisation Experience}

While performing in this concert, I experienced a way of improvising that was unique from how I improvise as either a music-centered music therapist or a performing musician. This way of improvising moved beyond the awareness of blurred disciplinary boundaries that I previously described experiencing in my clinical and performance work and began to outline (what is for me) a new and distinct way of improvising. I will describe how this unfolded during two pieces, "Rogerian Piece No. 2: Empathy" and "Life is...".

The instructions for the two performers in "Rogerian Piece No. 2: Empathy" are to improvise music in a way that demonstrates empathy for one another. While performing this piece, I drew upon my music therapist sensibilities. Empathy is one of the three ways of being that Carl Rogers identified as essential for therapists (Rogers, 1980) and is a foundation of my clinical work. I also drew upon my musical knowledge and skills as I typically do as a music therapist, analyzing the musical material and form, and using my technical abilities. Uniquely, I was additionally receiving an empathetic response to my own playing from the other performer; I was at once responsible for conveying empathy to the other musician and free to receive empathy. This affected me 
and influenced my music making in ways that are outside the role a music therapist. For example, by playing personal musical responses I engaged in freer and deeper musical self-disclosure ${ }^{6}$ than I do in my clinical work. I was also aware of the concert context. My music making was not only in the service of conveying empathy to the other performer; it was also an artistic expression and experience, an exploration, and a vehicle for sharing empathy with the audience. This context also influenced my experience of and participation in the improvisation.

"Life Is..." is a composition for small ensemble wherein each performer is asked to play a musical extract from a client's improvisation in a documented music therapy session $^{7}$. It is this musical motive that performers are instructed to use as the basis for their improvisations. While playing this piece, I drew upon my performance skills, such as interpreting the notated score and using my improvisational abilities to modify and expand upon the material I was given. In addition to this, I was aware that as an ensemble, we were each playing client material. Playing client material activated my clinical musicianship and therapeutic considerations. For example, I felt myself drawn to stay close to the original motive I was improvising from so that I could share it in a way that honoured that client and music therapy clients in general. This therapeutic sensibility coloured my performance of this piece.

These are examples of how I experienced this unique synthesis of improvisation practices throughout the concert. In performing these works, two ways that music therapy and music performance improvisation practices intersected also became clear.

\section{Material and Relational Interdisciplinarity}

I encountered two ways of linking the disciplines of music therapy and music performance in this concert; through materials and through relationships. I will explore each of these below. In the material experience of interdisciplinarity, the musical materials themselves served as the point of intersection between music therapy and music performance. For example, "Life Is..." (described in the above section and in Appendix A) is a deliberately crafted conversation between clients' musics and brought clinical material to the performance stage. The audience heard musical material created by people in music therapy sessions while being in the role of a traditional Western performance audience, listening to a composition being performed on-stage by trained musicians. Here the main area of intersection was located in the materials themselves, as music improvised during music therapy sessions was being performed without the intention of meeting the clinical aims of those clients.

The relational experience of interdisciplinarity between these improvisation practices speaks to the interpersonal, intrapersonal, intermusical, and intramusical relationships between performer(s) and audience. For example, during "Sounding the Emotional Aesthetic Environment," the ensemble improvised music based upon emotions and/or feelings suggested by the audience. In playing these emotions, I felt a sense of connection with the audience that was returned both tangibly (e.g. when an audience member cheered when their emotion was selected) and intangibly (e.g. the energy in the space). These interpersonal and intermusical relationships felt similar to my experiences in clinical improvisation when I musically match the emotional state of my client(s). Such interdisciplinary intersections also highlighted areas of tension between music therapy and music performance.

\section{Interdisciplinary Tensions: Use of Self, Artistry and Ethics}

In preparing for and performing this concert, I experienced tensions between my improvisation practices in music therapy and music performance that highlighted frictions between therapeutic use of self, music therapy ethics ${ }^{8}$, and music performance artistry. For example, during "Sounding the Emotional Aesthetic Environment," I performed the audience's emotions and feelings. During that performance, I felt myself drawing on the way I employ therapeutic use-of-self ${ }^{9}$ in sessions; I wanted to offer the audience an experience that was about their feelings and to hold an honouring space 
for the group. One part of my therapist self is that all the music I create is at the service of the client's health and wellbeing; I aim to recognize my musical biases and avoid making music based on my personal preferences or desires in the moment. This was in opposition with my performance sensibilities, where improvisation is a place for self-exploration and self-expression without responsibility for a 'therapeutic' audience experience.

I also felt tension between music therapy ethics and artistry by bringing client music into the performance space. In the music therapy models I work within, client music is confidential material and the client's permission is required to share it outside of the music therapy session. Though the musical extracts used in "Life Is..." are in the public domain (and therefore I had no legal responsibility as a performer to do so), as a music therapist I was aware of the special qualities and meaning of this music. I therefore contacted the authors of the case studies from which motives for "Life Is..." were drawn to ensure that they were comfortable with these motives being performed.

Alongside these reflections, this musical exploration of interdisciplinarity between improvisation practices in music therapy and music performance points towards additional areas worthy of consideration and further investigation.

\section{Improvised Musical Performance for Health and Wellbeing}

This pilot study pointed to a type of performance focused on health and wellbeing, and the special role of improvisation within such a concept, as vibrant areas of interdisciplinarity between improvisation in music therapy and music performance. More specifically, this concert suggests the potential for improvised performance to offer performers and audience members experiences that enhance their health and wellbeing by bringing clinical improvisation to the stage and modeling ways of being grounded in health and wellness.

\section{Performing Clinical Improvisation}

By employing clinical improvisation techniques as a performer (e.g. as I described occurred in "Rogerian Piece No. 2: Empathy") and performing motives from clients' clinical improvisations (ie. during "Life is..."), this research-creation project moves alongside Lee's concerts (Lee, 2011, 2016) in challenging the notions that clinical improvisation must occur in the context of a traditional music therapy session and be in the service of a particular client's clinical goals. This work affirms the potential for an emergent variation of clinical improvisation, wherein a goal may be to enhance the health and wellbeing of both the performers and the audience members without the presence of traditional clients. Such a performance practice allows the possibility for audiences to witness performers adopting aspects of a therapeutic use of self that includes modeling health and wellbeing.

\section{Performing Health and Wellbeing}

As a music therapy educator and supervisor, I aim to model wellbeing to my students, for example by practicing self-care and being transparent about my dedication to ongoing professional supervision and personal therapy. My intention in doing so is to implicitly encourage students to cultivate their own wellbeing and to provide a type of model for them of what they might like to move towards (Seabrook, 2012). Might it be similarly beneficial for an audience to witness an improvised performance of self that focuses on wellbeing? For example, "Three Rogerian Pieces" requires that ways of being that encourage health and wellness (congruence, empathy, and unconditional positive regard) are enacted and demonstrated to the audience by the performer(s). This is an opportunity for performers to explore these ways of being with themselves and each other. It is also an opportunity for the audience to witness wellness being modeled and thus to consider their own relationship to wellbeing. 
The concept of a performance focused on enhancing health and wellbeing also brings up a number of questions: As a performer within this genre, how effective or realistic is it to assume a broad health and wellness aim for a diverse audience? In intending such an aim for the audience, how might performers successfully navigate the subjectivity of musical experiences? When the intention of a concert is to enhance health and/or wellbeing, is there specific information that might be shared with or requested from audience members? Finally, what is the role of different musical activities within performance practices for health and wellbeing?

\section{The Special Role of Improvisation}

Music improvisation is "a unique psychological phenomenon distinct from other areas of musical activity" that "may therefore have an influence on health or wellbeing distinct from other musical behaviours" (MacDonald \& Wilson, 2014, p. 1). As such, improvisation can uniquely contribute to performances for health and wellbeing. For example, improvisation allows musicians to continually and dramatically adjust their performance in a given moment to better meet a perceived or articulated audience 'need' or an intended health and wellbeing aim. Additionally, the vulnerability and immediacy of improvised music performance uniquely impacts audience members; as Neeman articulates, there is a dynamic aliveness that results from being there in the moment of aesthetic creation that "cannot be fully captured for future reinterpretation" (2014, p. 39). It is within this dynamic immediacy that improvisation creates community between performer(s) and audience. Improvisation is a unique part of a performance for health and wellbeing landscape and worthy of further exploration as such.

\section{Sounding the Musical Potential: Ongoing Interdisciplinary Inquiry}

The findings of this research-creation pilot study are limited to the concert itself and my reflections. In future phases of the project I plan to collect audience and performer feedback so that an accurate understanding of these experiences is possible. Additionally, my reflections (both musical and written) are personal and subjective. As such, emergent concepts are not generalizable, and the discussion may not resonate with others. Furthermore, this project focused exclusively on Western Art Music notions of improvisation in music performance and it could be valuable for another researcher to similarly explore intersections between improvisation in music-centered music therapy and non-Western performance practices.

Potential exists to further musically investigate the interface between improvisation in music performance and music therapy; it is this interdisciplinarity, the exploration of the spaces between contexts and disciplines, which I find particularly rich and interesting.

\section{Concluding Thoughts}

I experienced a blurring between clinical and performance improvisation during this creative process. Indeed, such interdisciplinary investigation must be approached with caution, so that distinct improvisation practices are not misinterpreted or homogenized (Pavlicevic, 2000). Certainly music therapy and music performance are distinct fields, as are the improvisation practices within them. It is those special contexts that have allowed such unique improvisation practices to be developed and refined. Clinical improvisation continues to be necessary in music therapy, and music performance continues to require performance improvisation practices. They are, respectively, what serves the aims of those two disciplines best. However, as music performance becomes interested in therapeutic outcomes (e.g. Brandes, 2015), and music therapy becomes more integrated with performance practice (e.g. as in the case of community music therapy (Ansdell, 2005; Ansdell \& Stige, 2015)) it is helpful for diverse practitioners to dialogue. At their best, interdisciplinary explorations can serve to highlight what re- 
sides uniquely within the bounds of each discipline, link disciplines through common threads and illuminate new areas for collaboration and discovery.

\section{Acknowledgements}

I wish to thank the musicians who performed in the concert and whose improvisations made it the special event it was. Thank you also to Dr. Laurel Young who encouraged me to pursue this project as research-creation.

Special thanks and appreciation are extended to Dr. Colin Andrew Lee, whose pioneering work integrating music therapy, improvisation, and performance is the foundation upon which this project is built. Our conversations encouraged me and shaped my understanding of this topic.

\section{Notes}

1. Western art music is the improvisation and performance context I focused on for this study as it is where my training in expertise lies, thus allowing me to authentically interact with the material.

2. For the purposes of this paper, 'improvisation in music therapy' will be used interchangeably with 'clinical improvisation' as this reflects the author's perspective. The author acknowledges that there is disagreement in the music therapy community about whether these terms are interchangeable.

3. Music-centered music therapy theories posit a musically indigenous understanding of music therapy based on the music itself, which is seen as a container and vehicle for self-expression, self-exploration, and self-transformation (Aigen, 2005).

4. Free-improvisation is non-idomatic and trans-stylistic (Hickey, 2015) improvised music where improvisers "make decisions about what to do at any given moment based primarily on their own imagination and interpretation of the signal of others" (Pelz-Sherman, 1998, p. 5).

5. Recalling that it is also a part of the inquiry, as explained in the previous section.

6. Musical self-disclosure is the process of revealing information about oneself through musicmaking.

7. Musical extracts for "Life Is..." were taken from music therapy case studies in the public domain and additional consents for the use of these extracts was granted by all music therapists/authors involved.

8. Music therapists follow the code of ethics held by their respective governing body. In Canada, this is the Code of Ethics put forth by the Canadian Association of Music Therapists.

9. Use of self in therapy is the way that the therapist uses their self during sessions, including the personal and professional boundaries that they maintain, and how they enter into relationship with the person they are working with (Baldwin, 2013; Lum, 2002).

\section{References}

Aigen, K. (2005). Music-centered music therapy. Gilsum, NH: Barcelona.

Aigen, K. (2014). The study of music therapy. New York, NY: Routledge. https://doi.org/ $10.4324 / 9781315882703$.

Ansdell, G. (2005). Being who you aren't, doing what you can't. Voices: A World Forum for Music Therapy, 5(3), http://dx.doi.org/10.15845/voices.v5i3.229.

Ansdell, G., \& Stige, B. (2015). Community music therapy. In J. Edwards (Ed.), The Oxford handbook of music therapy. Retrieved from, http://www.oxfordhandbooks.com.proxy3.1ibrary.mcgill.ca/view/10.1093/oxfordhb/ 9780199639755.001.0001/oxfordhb-9780199639755-e-6, http://dx.doi.org/10.1093/ oxfordhb/9780199639755.013.6. 
Austin, D., Mahoney, J., Courter, A., Ryan, K., Starace, J., \& Defeo, N. (2016). Artists' reflections on preparing and performing the arts-based research study "Grace Street". Music Therapy Perspectives, 34(1), 48-51, http://dx.doi.org/https://doi.org/10.1093/mtp/miw001.

Baldwin, M. (2013). Introduction. In M. Baldwin (Ed.), The use of self in therapy (3rd ed., pp. 1-18). New York, NY: Routledge. http://dx.doi.org/https://doi.org/10.4324/ 9780203076156.

Brandes, D. (2015). Composing Sabbath spaces: Thoughts and reflections on making quiet music. Retrieved from, https://weirdcanada.com/2015/03/ideas-composing-sabbath-spacesthoughts-and-reflections-on-making-quiet-music/.

Bruscia, K. (2014). Defining music therapy (3rd ed.). University Park, IL: Barcelona.

Chapman, O., \& Sawchuck, K. (2012). Research-creation: Intervention, analysis and "family resemblances". Canadian Journal of Communication, 37(1), http://dx.doi.org/ http://dx.doi.org/10.22230/cjc.2012v37n1a2489.

Cobussen, M. (2014). Aesthetic sensibility and artistic sonification. In M. Schwab \& H. Borgdorff (Eds.), The exposition of artistic research: Publishing art in academia (pp. 65-77). Leiden, Holland: Leiden University.

Gardstrom, S. C. (2007). Music therapy improvisation for groups: Essential leadership competencies. Gilsum, NH: Barcelona.

Gordon, S. (2006). Mastering the art of performance: A primer for musicians. New York, NY: Oxford University Press. https://doi.org/10.1093/acprof:oso/9780195177435.001.0001.

Hickey, M. (2015). Learning from the experts: A study of free-improvisation pedagogues in university settings. Journal of Research in Music Education, 62(4), 425-445, http://dx.doi.org/https://doi.org/10.1080/14613808.2015.1016493.

Kershaw, B. (2009). Practice as research through performance. In H. Smith \& R. Dean (Eds.), Practice-led research, research-led practice in the creative arts (pp. 104-125). Edinburgh, Scottland: Edinburgh University Press.

Lee, C. A. (2003). The architecture of aesthetic music therapy. Gilsum, NH: Barcelona.

Lee, C. A. (2011). Improvisations on client themes. Waterloo, Ontario: Wilfrid Laurier University.

Lee, C. A. (2016). Music for contemplative landscapes. Waterloo, Ontario: Wilfrid Laurier University.

Lee, C. A., \& Houde, M. (2011). Improvising in styles. A workbook for music therapists, educators and musicians. Gilsum, NH: Barcelona.

Lum, W. (2002). The use of self of the therapist. Contemporary Family Therapy, 24(1), 181-197, http://dx.doi.org/https://doi.org/10.1023/a:1014385908625.

MacDonald, R. A., \& Wilson, G. (2014). Musical improvisation and health: A review. Psychology of Wellbeing, 4(20), Retrieved from, https://psywb.springeropen.com/articles/ 10.1186/s13612-014-0020-9, http://dx.doi.org/10.1186/s13612-014-0020-9.

Nachmanovitch, S. (1991). Free play. New York, NY: Jeremy P. Tarcher/Putnam.

Neeman, E. (2014). Free improvisation as a performance technique: Group creativity and interpreting graphic scores (Doctor of Musical Arts). Retrieved from, http://www.edwardneeman.com/FreeImprovisationAsAPerformanceTechnique.pdf.

Nordoff, P., Robbins, C., \& Marcus, D. (2007). Creative music therapy: A guide to fostering clinical musicianship. Gilsum, NH: Barcelona.

Pavlicevic, M. (2000). Improvisation in music therapy: Human communication in sound. Journal of Music Therapy, 37(4), 269-285, http://dx.doi.org/https://doi.org/10.1093/jmt/ 37.4.269.

Pelz-Sherman, M. (1998). A framework for the anlaysis of performer interactions in Western improvised contemporary art music (PhD dissertation). San Diego: University of California.

Reisner, R. (1977). Bird: The legend of Charlie Parker. New York, NY: Da Capo Press.

Rogers, C. (1980). A way of being. New York, NY: Houghton Mifflin Company. 
Seabrook, D. (2012, May). Modelling wellness: The challenge and necessity of teaching self-care to music therapy students. Paper presented at the $38^{\text {th }}$ annual Canadian Association for Music Therapy Conference, Montréal, QC.

Seabrook, D., \& Arnason, C. (2010). Reflections on arts-based research: The experience of two music therapists. Voices: A world forum for music therapy, 10(1), http://dx.doi.org/ https://doi.org/10.15845/voices.v10i1.154.

Social Sciences and Humanities Research Council. (2016). Definitions of terms. Retrieved from http://www.sshrc-crsh.gc.ca/funding-financement/programs-programmes/definitionseng.aspx\#a22

Viega, M. (2016). Aesthetic sense and sensibility: Arts-based research and music therapy. Music Therapy Perspectives, 31(1), 1-3, http://dx.doi.org/https://doi.org/10.1093/mtp/ miw010.

Viega, M., \& Forinash, M. (2016). Arts-based research. In K. Murphy \& B. Wheeler (Eds.), Music therapy research (3rd ed., pp. 491-504). Dallas, TX: Barcelona.

Wigram, T. (2004). Improvisation: Methods and techniques for music therapy clinicians, educators, and students. London, England: Jessica Kingsley Publishers.

Young, L., \& Nichol, J. J. (2011, August). Perspectives on singing and performing in music therapy. Paper presented at the International symposium on performance science, Toronto, Canada. 